\title{
Qualitative and quantitative assessment of selected Melli bank branches in northern Tehran by using data envelopment analysis based on the balanced scored card in Iran
}

\author{
${ }^{1}$ Bizhan Nosrati Barandagh, ${ }^{2}$ Zeinolabedin amini sabegh \\ 1, Student of Industrial management, Science and Research branch, Islamic Azad University, Saveh, Iran. \\ ${ }^{2}$. Departmen ${ }^{t}$ of Public management, Islamic Azad University, saveh branch, Saveh, Iran
}

\begin{abstract}
In today's competitive world, many manufacturing and service companies have been forced to take up new approaches to management. Among these approaches, we can point to one of the new methods of performance evaluation called data envelopment analysis technique that has an important role in improving the performance of an organization. Among challenges of this technique is to select appropriate indicators in order to introduce input and output variables for DEA, therefore the approach of balanced scored card (BSC) is used to mitigate this challenge that as a new tool for performance evaluation allows the research variables to be explained in order to be employed in DEA technique based on a holistic vision and various organizational aspects (financial, internal processes, customer, growth and learning). In this study, we tried to measure the efficiency of 48 top and grade-one branches of Tehran-North in the 2013 timeframe, not only the financially, but also the aspects of financial, customer, internal process and learning and growth; by combining the DEA-BSC technique and with the model of "yield super-efficiency in constant scale of DEA enveloping input-oriented form" that is capable to announce the efficiency ranking for units and to rank the efficient units simultaneously. The results showed that average efficiency rate from four perspectives: financial, customer, internal process and learning and growth of BSC model is $0.68,0.63,0.44,0.65$, respectively, and in total, the average efficiency of branches is 0.6 in this year and it indicates that the most major alignment with macro-strategies of branches is in the financial perspective. Also, Anahita branch was introduced as the most efficient unit from each four perspectives of the BSC model in compared to the other branches.
\end{abstract}

Keywords: Efficiency Evaluation, Data Envelopment Analysis, Balanced Scored card, Composition of DEABSC, DEA Super Efficient Models.

\section{Introduction}

In a world where modern technology is growing every day through computer and telecommunications and creates an intense competition context for organizations, performance evaluation and modeling has become as a tool for continuous improvement for commercial units. Performance evaluation system has undergone significant changes in compared to the past. The results of measurements is true, if the action of comparison to be conducted for similar with similar and yesterday with today. Different methods have been developed for measuring and evaluating performance, that the managers of organizations take advantage of certain models according to the purpose of the assessment and the type of organization or design the required model with the combination of several models. One of the performance evaluation methods is Data Envelopment Analysis. The approach of data envelopment analysis with a focus on balanced scored card is considered as a new method of performance evaluation, in fact the approach of balanced scored card allows the research inputs and outputs selection to be explained in order to be employed in DEA technique based on a holistic vision and various organizational aspects (financial, internal processes, customer, growth and learning). Therefore in this study, we tried to measure the efficiency of top and grade-one Melli bank branches in northern Tehran with combination of DEA and BSC models.

\section{Problem Statement}

Today, due to intense competition, speed, volume of information and the challenges facing organizations, it is more than ever essential to have performance evaluation models in order to determine the position of organization and also to develop the strategic planning based on the strengths and weaknesses of the organization. Generally, the performance evaluation can be defined as a system by which a company can monitor the daily operations and assess the fulfillment of its goals. The issue of performance evaluation of banks' branches is also a challengeable decision-making which is always facing decision-makers and managers. This issue needs multi-criteria decisions associated with the overall objectives and mission of banks, strategic potentials and probability of technical and commercial success. Therefore this study has measured the efficiency 
of top and grade-one Melli bank branches in northern Tehran in 2013 with combination of DEA and BSC models.

Given the above, the main research questions are as follows:

- Does the combination of two models of DEA and BSC provide appropriate tools for performance evaluation of banks?

- Do the top and grade-one branches of Tehran-North work efficiently?

Research objectives:

Given that the importance of companies' performance evaluation and that nowadays one of the most important issues in companies' finance is the measure of their performance and to what extent the companies have attempted to increase the interests of their shareholders, and what indicators are being considered by banks and credit institutions in granting facilities to companies,

So, the scientific objectives are the study will be:

- To provide a comprehensive and hybrid model by the tools of "balanced scored card" and " Data Envelopment Analysis" to evaluate the top and grade-one Melli bank branches in northern Tehran

- To evaluate the top and grade-one Melli bank branches in northern Tehran by super efficient models of " Data Envelopment Analysis"

And applied objectives of the research will be:

- To provide an improved method to prioritize banks

- To demonstrate the importance of the banks' efficiency for development of capital markets, and country's economic.

- To determine the branches of reference Mellil Bank as a pattern unit

- To show the importance of modeling for top and grade-one inefficient Melli bank branches in northern Tehran, from efficient branches in order to speed up the improvement process of these units, reduction in costs, and more profitably

- To create a context for planning and targeting the branches' managers, in order to use available resources optimally, identify balanced score, according to the efficiency score estimated by DEA technique

\section{Research Questions:}

This study is to answer the following questions:

\section{Main Question:}

- Does the combination of two models of DEA and BSC provide appropriate tools for performance evaluation of banks?

- Do the top and grade-one branches of Tehran-North work efficiently?

\section{Sub-questions:}

- Can appropriate indicators be offered by model BSC to evaluate the performance of DEA technique for top and grade-one Melli bank branches in northern Tehran?

- What extent is the efficiency score of investigated units?

- What are the pattern units?

\section{Collection and analysis of data / information}

In this study, library and field methods are used to collect data in a way that at first, library approach is used for data collection for the research literature and finally, information about the variables was collected from the balance sheet, profit and loss account, recommendation system database, office of human capital and employees' personnel files of top and grade-one Melli bank branches in northern Tehran, existing databases of the Melli Bank, in order to collect data related to the input and output variables taken from four perspectives of model BSC, by the researcher. "The enveloping form of the model of super-efficiency under return in constant scale of input nature" related to DEA is used for data analysis in the general case and is analyzed by GAMS software.

\section{Analyzing the results of $\mathrm{BSC}$ model in financial perspective \\ - Branch of Khwaja Abdullah Ansari:}


According to the data collected in the third chapter, the general form of the model of Enveloping Input-Oriented Super-Efficient in order to obtain technical efficiency score of mentioned branch in financial perspective will be as follows:

It should be explained that the value of $\mathrm{s}$ was used for zero due to avoid error in computing in GAMS software. $\min Z_{0}=\theta$

$$
\begin{aligned}
& s t \\
& \lambda_{1} 0.12+\lambda_{2} 0.2+\lambda_{3} 0.7+\lambda_{4} 0.22+\lambda_{5} 0.3+\ldots \ldots .+\lambda_{48} 0.2 \leq \theta 0.43 \\
& \lambda_{1} 0.65+\lambda_{2} 0.85+\lambda_{3} 0.15+\lambda_{4} 0.32+\lambda_{5} 0.03+\ldots \ldots \ldots . \lambda_{48} 0.42 \leq \theta 0.1 \\
& \lambda_{1} 0.33+\lambda_{2} 0.12+\lambda_{3} 0.24+\lambda_{4} 0.23+\lambda_{5} 0.02+\ldots \ldots . \lambda_{48} 0.56 \leq \theta 0.65 \\
& \lambda_{1} 0.54+\lambda_{2} 0.03+\lambda_{3} 0.02+\lambda_{4} 0.09+\lambda_{5} 0.06+\ldots \ldots .+\lambda_{48} 0.002 \geq 0.02 \\
& \lambda_{1} 0.8+\lambda_{2} 0.75+\lambda_{3} 0.55+\lambda_{4} 0.45+\lambda_{5} 0.2+\ldots \ldots . .+\lambda_{48} 0.002 \geq 0.23 \\
& \lambda_{1} 0.7+\lambda_{2} 1+\lambda_{3} 0.3+\lambda_{4} 0.45+\lambda_{5} 0.23+\ldots \ldots .+\lambda_{48} 0.25 \geq 0.2 \\
& \lambda_{1} \geq 0, \\
& \lambda_{2} \geq 0, \\
& \lambda_{3} \geq 0, \\
& . \\
& . \\
& \lambda_{48} \geq 0,
\end{aligned}
$$

Above model is capable to calculate the efficiency score and determine the model units for the branch of Khajeh Abdollah Ansari in financial perspective.

The second phase of above model in order to calculate the surplus and shortage amounts for the branch is as follows.

$$
\begin{aligned}
\max w & =S_{1}^{-}+s_{2}^{-}+s_{3}^{-}+s_{1}^{+}+s_{2}^{+}+s_{3}^{+} \\
& s t \\
& \lambda_{1} 0.12+\lambda_{2} 0.2+\lambda_{3} 0.7+\lambda_{4} 0.22+\lambda_{5} 0.3+\ldots \ldots .+\lambda_{48} 0.2+s_{1}^{-}=\theta 0.43 \\
& \lambda_{1} 0.65+\lambda_{2} 0.85+\lambda_{3} 0.15+\lambda_{4} 0.32+\lambda_{5} 0.03+\ldots \ldots \ldots+\lambda_{48} 0.42+s_{2}^{-}=\theta 0.1 \\
& \lambda_{1} 0.33+\lambda_{2} 0.12+\lambda_{3} 0.24+\lambda_{4} 0.23+\lambda_{5} 0.02+\ldots \ldots+\lambda_{48} 0.56+s_{3}^{-}=\theta 0.65 \\
& \lambda_{1} 0.54+\lambda_{2} 0.03+\lambda_{3} 0.02+\lambda_{4} 0.09+\lambda_{5} 0.06+\ldots \ldots . .+\lambda_{48} 0.002-s_{1}^{+}=0.02 \\
& \lambda_{1} 0.8+\lambda_{2} 0.75+\lambda_{3} 0.55+\lambda_{4} 0.45+\lambda_{5} 0.2+\ldots \ldots . .+\lambda_{48} 0.002-s_{2}^{+}=0.23 \\
& \lambda_{1} 0.7+\lambda_{2} 1+\lambda_{3} 0.3+\lambda_{4} 0.45+\lambda_{5} 0.23+\ldots \ldots+\lambda_{48} 0.25-s_{3}^{+}=0.2 \\
& \lambda_{1} \geq 0, \\
& \lambda_{2} \geq 0 \\
& \lambda_{3} \geq 0 \\
& \cdot \\
& \cdot \\
& \lambda_{48} \geq 0
\end{aligned}
$$

The result of the above model will calculated the surplus and shortage amounts during the providing services for the branch of Khwaja Abdullah Ansari.

The overall output of software GAMS for the model of "enveloping input-oriented super-efficiency under return in constant scale" with financial perspective data for 48 units is as follows:

Table 1 the total output of the software GAMS for 48 branches, financial perspective 


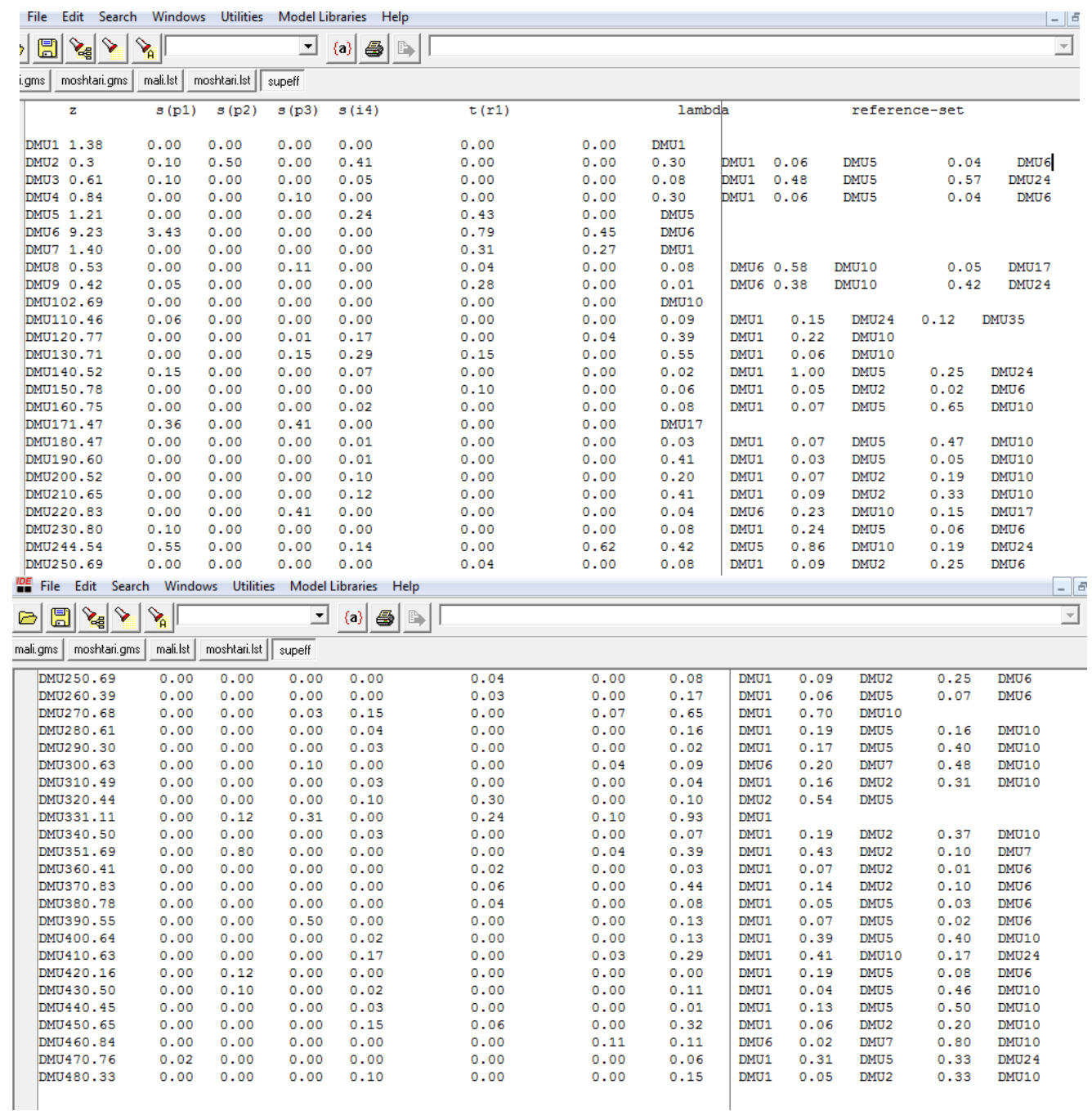

Based on the table, the technical efficiency score of the branch of "Khwaja Abdullah Ansari" in financial perspective is 0.3. As shown in Table, the reason of inefficiency in mentioned branch is 0.04 shortages in the variable of return on assets rate in outputs toward its potential and confirms the conclusion that because of this weakness, it hasn't reach common financial goals of profitability, growth and shareholder value in financial perspective toward the other branches. As described, DEA models allow the units of the model to be determine, for example the reference units of Anahita, Zafar St., Pasdaran have been introduced as a model unit for the branch of Khwaja Abdullah Ansari, the weight of reference branch $\lambda$ is the coefficient which is shown in Table and shows the participation rate of the reference branches in the assessment of inefficient branches. For example coefficient $\lambda$ (Shadow Prices) with score 0.02 in fact indicates that the similarity of Khwaja Abdullah Ansari unit for modeling from reference model is 0.02 higher than any other reference units, that finally, with the composition of reference units of Anahita, Zafar St., Pasdaran, a virtual unit will be achieved as follows:

$0.02\left[\begin{array}{l}0.12 \\ 0.17 \\ 0.4\end{array}\right]=\left[\begin{array}{l}0.002 \\ 0.003 \\ 0.008\end{array}\right]$ As can be seen, the inputs of virtual unit is equal to $\left[\begin{array}{l}0.002 \\ 0.003 \\ 0.008\end{array}\right]$, while the real input of the branch of Khwaja Abdullah Ansari is $\left[\begin{array}{l}0.43 \\ 0.1 \\ 0.65\end{array}\right]$. According to this results, the surplus amounts of use in

resources and shortage of output related to the model of enveloping input-oriented super-efficient indicates that the amount of output shortage in the variable of return on assets rate has caused to obtain score 0.3 in technical efficiency. Also, as it was said before, the model of enveloping input-oriented super-efficient, in addition to 
calculating the efficiency score is capable to tank the efficient units that the ranking of efficiency units for financial perspective is as follows:

Table 1: The ranking of efficiency units for financial perspective

\begin{tabular}{|c|c|c|}
\hline Efficiency Score & Branch Name & Unit \\
\hline 2.69 & Pasdaran & 10 \\
\hline 1.69 & International Exhibition & 35 \\
\hline 1.44 & Afrigha & 2 \\
\hline 1.47 & Seyyed Jamal Al-din Asad Abadi St. & 17 \\
\hline 1.38 & Anahita & 1 \\
\hline 1.35 & Parsa & 23 \\
\hline 1.21 & Zafar St. & 5 \\
\hline
\end{tabular}

\section{Analyzing the results of BSC model in customer perspective}

- Branch of Khwaja Abdullah Ansari:

According to the data collected in the third chapter, the general form of the model of Enveloping Input-Oriented Super-Efficient in order to obtain technical efficiency score of mentioned branch in customer perspective will be as follows:

It should be explained that the value of $\varepsilon=0.00001$ was used for zero due to avoid error in computing in GAMS software.

$$
\begin{aligned}
& \min Z_{0}=\theta \\
& \text { st } \\
& \lambda_{1} 0.3+\lambda_{2} 0.55+\lambda_{3} 0.33+\lambda_{4} 0.37+\lambda_{5} 0.73+\ldots \ldots .+\lambda_{48} 0.13 \leq \theta 0.3 \\
& \lambda_{1} 0.5+\lambda_{2} 0.4+\lambda_{3} 0.2+\lambda_{4} 0.45+\lambda_{5} 0.5+\ldots \ldots \ldots+\lambda_{48} 0.23 \leq \theta 0.35 \\
& \lambda_{1} 0.33+\lambda_{2} 0.42+\lambda_{3} 0.04+\lambda_{4} 0.13+\lambda_{5} 0.62+\ldots \ldots . .+\lambda_{48} 0.56 \geq 15 \\
& \lambda_{1} 1+\lambda_{2} 0.73+\lambda_{3} 0.2+\lambda_{4} 0.9+\lambda_{5} 0.6+\ldots \ldots . .+\lambda_{48} 0.2 \geq 0.2 \\
& \lambda_{1} 0.35+\lambda_{2} 1+\lambda_{3} 0.003+\lambda_{4} 0.09+\lambda_{5} 0.2+\ldots \ldots . .+\lambda_{48} 0.15 \geq 0.23 \\
& \lambda_{1} \geq 0, \\
& \lambda_{2} \geq 0, \\
& \lambda_{3} \geq 0, \\
& . \\
& . \\
& \lambda_{48} \geq 0,
\end{aligned}
$$

Above model is capable to calculate the efficiency score and determine the model units for the branch of Khajeh Abdollah Ansari in internal process customer perspective.

The second phase of above model in order to calculate the surplus and shortage amounts for the branch is as follows.

$\max w=s_{1}^{-}+s_{2}^{-}+s_{1}^{+}+s_{2}^{+}+s_{3}^{+}$ 
st

$$
\begin{aligned}
& \lambda_{1} 0.3+\lambda_{2} 0.55+\lambda_{3} 0.33+\lambda_{4} 0.37+\lambda_{5} 0.73+\ldots \ldots . .+\lambda_{48} 0.13+s_{1}^{-}=\theta 0.3 \\
& \lambda_{1} 0.5+\lambda_{2} 0.4+\lambda_{3} 0.2+\lambda_{4} 0.45+\lambda_{5} 0.5+\ldots \ldots \ldots .+\lambda_{48} 0.23+s_{2}^{-}=\theta 0.35 \\
& \lambda_{1} 0.33+\lambda_{2} 0.42+\lambda_{3} 0.04+\lambda_{4} 0.13+\lambda_{5} 0.62+\ldots \ldots . .+\lambda_{48} 0.56-s_{1}^{+}=15 \\
& \lambda_{1} 1+\lambda_{2} 0.73+\lambda_{3} 0.2+\lambda_{4} 0.9+\lambda_{5} 0.6+\ldots \ldots . .+\lambda_{48} 0.2-s_{2}^{-}=0.2 \\
& \lambda_{1} 0.35+\lambda_{2} 1+\lambda_{3} 0.003+\lambda_{4} 0.09+\lambda_{5} 0.2+\ldots \ldots . .+\lambda_{48} 0.15-s_{3}^{-}=0.23 \\
& \lambda_{1} \geq 0, \\
& \lambda_{2} \geq 0, \\
& \lambda_{3} \geq 0,
\end{aligned}
$$

$\lambda_{48} \geq 0$

The result of the above model will calculated the surplus and shortage amounts during the providing services for the branch of Khwaja Abdullah Ansari.

The overall output of software GAMS for the model of "enveloping input-oriented super-efficiency under return in constant scale" with customer perspective data for 48 units is as follows:

Table 3: The total output of the software GAMS for 48 branches, customer perspective

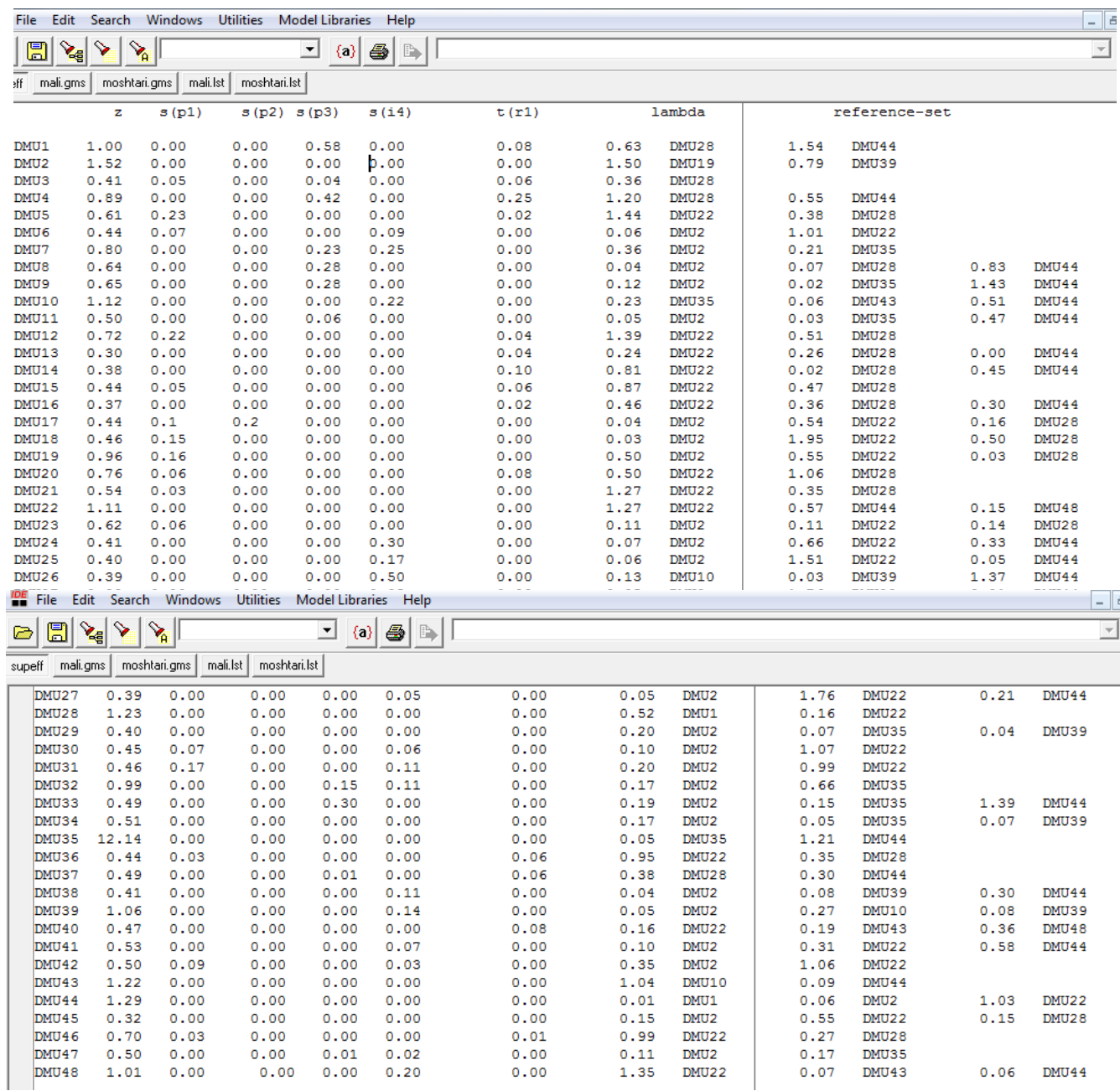

Based on the table, the technical efficiency score of the branch of "Khwaja Abdullah Ansari" in customer perspective is 0.4. As shown in Table, the reason of inefficiency in the branch of Khwaja Abdullah Ansar is the surplus amounts of using inputs in amount of advertising and marketing cost, and shortage 0.2 in gaining the market share, toward its potential. Indeed, lack of cost management and lack of adequate programs in advertising has been caused the shortage in attracting customers. In fact, the branch has been poor in customer 
service in compared to other branches due to the mentioned weakness. As described, DEA models allow the units of the model to be determine, for example the reference units of Afrigha, International exhibition, Elahiyeh Golnar Tower, Dezaship have been introduced as a model unit for the branch of Khwaja Abdullah Ansari, the weight of reference branch $\lambda$ is the coefficient and indicates the participation rate of the reference branches in the assessment of inefficient branches. That finally, with the composition of mentioned reference units, a virtual unit will be achieved as follows:

$$
0.2\left[\begin{array}{l}
0.55 \\
0.4
\end{array}\right]+0.07\left[\begin{array}{l}
0.01 \\
0.65
\end{array}\right]+0.04\left[\begin{array}{l}
0.09 \\
0.2
\end{array}\right]+0.03\left[\begin{array}{l}
0.1 \\
0.23
\end{array}\right]=\left[\begin{array}{l}
0.1 \\
0.14
\end{array}\right]
$$

As can be seen, the inputs of virtual unit is equal to $\left[\begin{array}{l}0.1 \\ 0.14\end{array}\right]$, while the real input of the branch of Khwaja Abdullah Ansari is $\left[\begin{array}{l}0.3 \\ 0.35\end{array}\right]$. The ranking of efficiency units for customer perspective is as follows:

Table 2: The ranking of efficiency units for customer perspective

\begin{tabular}{|c|c|c|}
\hline Efficiency Score & Branch Name & Units \\
\hline 12.14 & Sepehr & 25 \\
\hline 1.52 & Afrigha & 2 \\
\hline 1.29 & Dezaship & 44 \\
\hline 1.23 & pesian & 28 \\
\hline 1.22 & Zaferanieh & 43 \\
\hline 1.21 & Pasdaran & 10 \\
\hline 1.11 & Mother Square & 22 \\
\hline 1.01 & efficiency & 10 \\
\hline 1.09 & Elahiyeh Golnar Tower & 39 \\
\hline 1.01 & Velenjak & 48 \\
\hline 1 & Anahita & 1 \\
\hline
\end{tabular}

\section{Analyzing the results of BSC model in internal process perspective:}

- Branch of Khwaja Abdullah Ansari:

According to the data collected in the third chapter, the general form of the model of Enveloping Input-Oriented Super-Efficient in order to obtain technical efficiency score of mentioned branch in customer perspective will be as follows:

It should be explained that the value of $\varepsilon=0.00001$ was used for zero due to avoid error in computing in GAMS software.

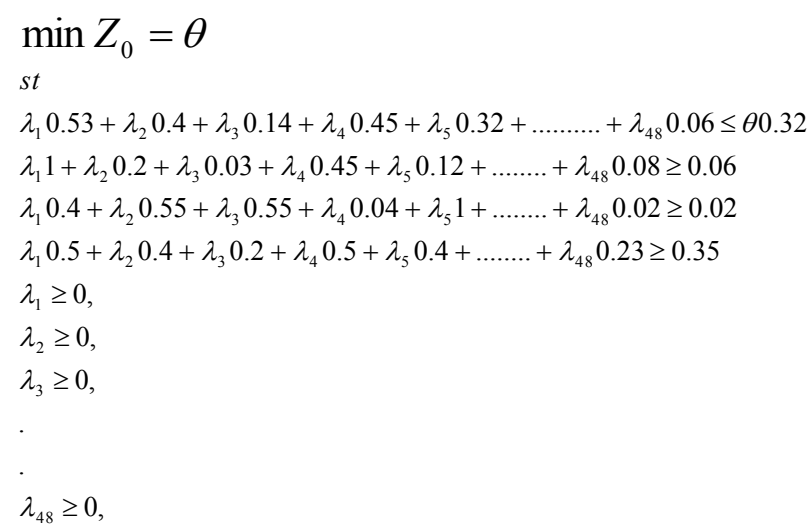

This model is capable to calculate the amounts of input surplus and output shortage. 


$$
\begin{aligned}
& \max w=s_{1}^{-}+s_{1}^{+}+s_{2}^{+}+S_{3}^{+} \\
& \text {st } \\
& \lambda_{1} 0.53+\lambda_{2} 0.4+\lambda_{3} 0.14+\lambda_{4} 0.45+\lambda_{5} 0.32+\ldots \ldots \ldots .+\lambda_{48} 0.06+s_{1}^{-}=\theta 0.32 \\
& \lambda_{1} 1+\lambda_{2} 0.2+\lambda_{3} 0.03+\lambda_{4} 0.45+\lambda_{5} 0.12+\ldots \ldots .+\lambda_{48} 0.08-s_{1}^{+}=0.06 \\
& \lambda_{1} 0.4+\lambda_{2} 0.55+\lambda_{3} 0.55+\lambda_{4} 0.04+\lambda_{5} 1+\ldots \ldots . .+\lambda_{48} 0.02-s_{2}^{+}=0.02 \\
& \lambda_{1} 0.5+\lambda_{2} 0.4+\lambda_{3} 0.2+\lambda_{4} 0.5+\lambda_{5} 0.4+\ldots \ldots . .+\lambda_{48} 0.23-s_{3}^{+}=0.35 \\
& \lambda_{1} \geq 0 \\
& \lambda_{2} \geq 0, \\
& \lambda_{3} \geq 0, \\
& . \\
& . \\
& \lambda_{48} \geq 0,
\end{aligned}
$$

The overall output of software GAMS for the model of "enveloping input-oriented super-efficiency under return in constant scale" with internal process perspective data for 48 units is as follows:

Table 3: The total output of the software GAMS for 48 branches, internal process perspective

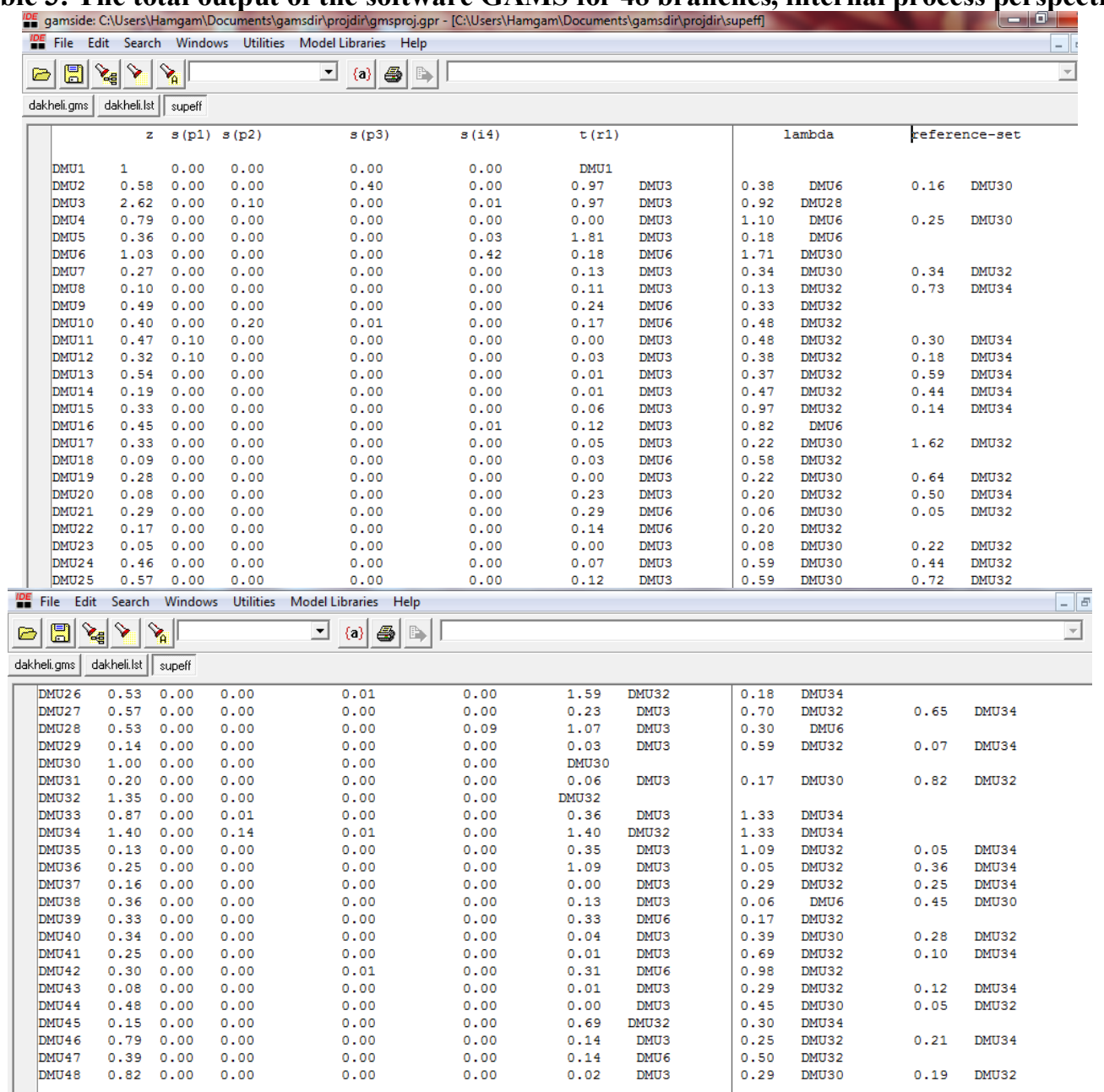

Based on the table, the technical efficiency score of the branch of "Khwaja Abdullah Ansari" in financial perspective is 0.14. As shown in Table, the reason of inefficiency in mentioned branch is surplus amounts of the costs of new banking services in the amount 0.1.In fact, internal activities of the branch including the provision of modern banking services to attract customers have been with lack of cost management in the context of modern banking services more than other branches. According to data, the units of Momtaz Melli, Pardis, Zebarjad have been introduced as a model unit for the inefficient branch of Khwaja Abdullah Ansari in 
internal process perspective. And finally, with the composition of reference units, a virtual unit will be achieved as follows:

$$
0.03[0.14]+0.59[0.06]+0.07[0.06]=[0.04]
$$

As can be seen, the inputs of virtual unit is equal to [0.04], while the real input of the branch of Pasdaran is $[0.4]$. The ranking of efficiency units for internal process perspective is also as follows:

Table 4: The ranking of efficiency units for internal process perspective

\begin{tabular}{|c|c|c|}
\hline Efficiency Score & Branch Name & Units \\
\hline 2.62 & Momtaz Melli & 3 \\
\hline 1.35 & Pardis & 32 \\
\hline 1.03 & Dr. Shariati & 6 \\
\hline 1 & Anatita & 1 \\
\hline 1 & Mokhaberat & 30 \\
\hline
\end{tabular}

\section{Analyzing the results of BSC model in Growth and Learning perspective}

- Branch of Khwaja Abdullah Ansari:

According to the data collected in the third chapter, the general form of the model of Enveloping Input-Oriented Super-Efficient in order to obtain technical efficiency score of mentioned branch in Growth and Learning perspective will be as follows:

It should be explained that the value of $\varepsilon=0.00001$ was used for zero due to avoid error in computing in GAMS software.

$$
\min Z_{0}=\theta
$$

st

$\lambda_{1} 0.12+\lambda_{2} 0.2+\lambda_{3} 0.7+\lambda_{4} 0.22+\lambda_{5} 0.3+\ldots \ldots .+\lambda_{48} 0.2 \leq \theta 0.3$

$\lambda_{1} 0.65+\lambda_{2} 0.75+\lambda_{3} 0.15+\lambda_{4} 0.32+\lambda_{5} 0.03+\ldots \ldots \ldots .+\lambda_{48} 0.42 \leq \theta 0.24$

$\lambda_{1} 0.03+\lambda_{2} 0.12+\lambda_{3} 0.24+\lambda_{4} 0.13+\lambda_{5} 0.02+\ldots \ldots . .+\lambda_{48} 0.46 \geq 0.23$

$\lambda_{1} 0.54+\lambda_{2} 0.03+\lambda_{3} 0.02+\lambda_{4} 0.09+\lambda_{5} 0.06+\ldots \ldots . .+\lambda_{48} 0.002 \geq 0.002$

$\lambda_{1} 0.8+\lambda_{2} 0.75+\lambda_{3} 0.55+\lambda_{4} 0.45+\lambda_{5} 0.2+\ldots \ldots . .+\lambda_{48} 0.25 \geq 0.23$

$\lambda_{1} 0.03+\lambda_{2} 1+\lambda_{3} 0.3+\lambda_{4} 0.45+\lambda_{5} 0.23+\ldots \ldots . .+\lambda_{48} 0.5 \geq 0.2$

$\lambda_{1} \geq 0$,

$\lambda_{2} \geq 0$

$\lambda_{3} \geq 0$

$\lambda_{48} \geq 0$,

This model is capable to calculate the amounts of input surplus and output shortage.

$\max w=s_{1}^{-}+s_{1}^{+}+s_{2}^{+}+s_{3}^{+}$ 
$s t$

$$
\begin{aligned}
& \lambda_{1} 0.12+\lambda_{2} 0.2+\lambda_{3} 0.7+\lambda_{4} 0.22+\lambda_{5} 0.3+\ldots \ldots . .+\lambda_{48} 0.2+s_{1}^{-}=\theta 0.3 \\
& \lambda_{1} 0.65+\lambda_{2} 0.75+\lambda_{3} 0.15+\lambda_{4} 0.32+\lambda_{5} 0.03+\ldots \ldots \ldots .+\lambda_{48} 0.42+s_{2}^{-}=\theta 0.24 \\
& \lambda_{1} 0.03+\lambda_{2} 0.12+\lambda_{3} 0.24+\lambda_{4} 0.13+\lambda_{5} 0.02+\ldots \ldots . .+\lambda_{48} 0.46-s_{1}^{+}=0.23 \\
& \lambda_{1} 0.54+\lambda_{2} 0.03+\lambda_{3} 0.02+\lambda_{4} 0.09+\lambda_{5} 0.06+\ldots \ldots .+\lambda_{48} 0.002-s_{2}^{+}=0.002 \\
& \lambda_{1} 0.8+\lambda_{2} 0.75+\lambda_{3} 0.55+\lambda_{4} 0.45+\lambda_{5} 0.2+\ldots \ldots . .+\lambda_{48} 0.25-s_{3}^{+}=0.23 \\
& \lambda_{1} 0.03+\lambda_{2} 1+\lambda_{3} 0.3+\lambda_{4} 0.45+\lambda_{5} 0.23+\ldots \ldots . .+\lambda_{48} 0.5-s_{4}^{+}=0.2 \\
& \lambda_{1} \geq 0, \\
& \lambda_{2} \geq 0, \\
& \lambda_{3} \geq 0,
\end{aligned}
$$

$\lambda_{48} \geq 0$,

The overall output of software GAMS for the model of "enveloping input-oriented super-efficiency under return in constant scale" with Growth and Learning perspective data for 48 units is as follows:

Table 5: The total output of the software GAMS for 48 branches, Growth and Learning perspective

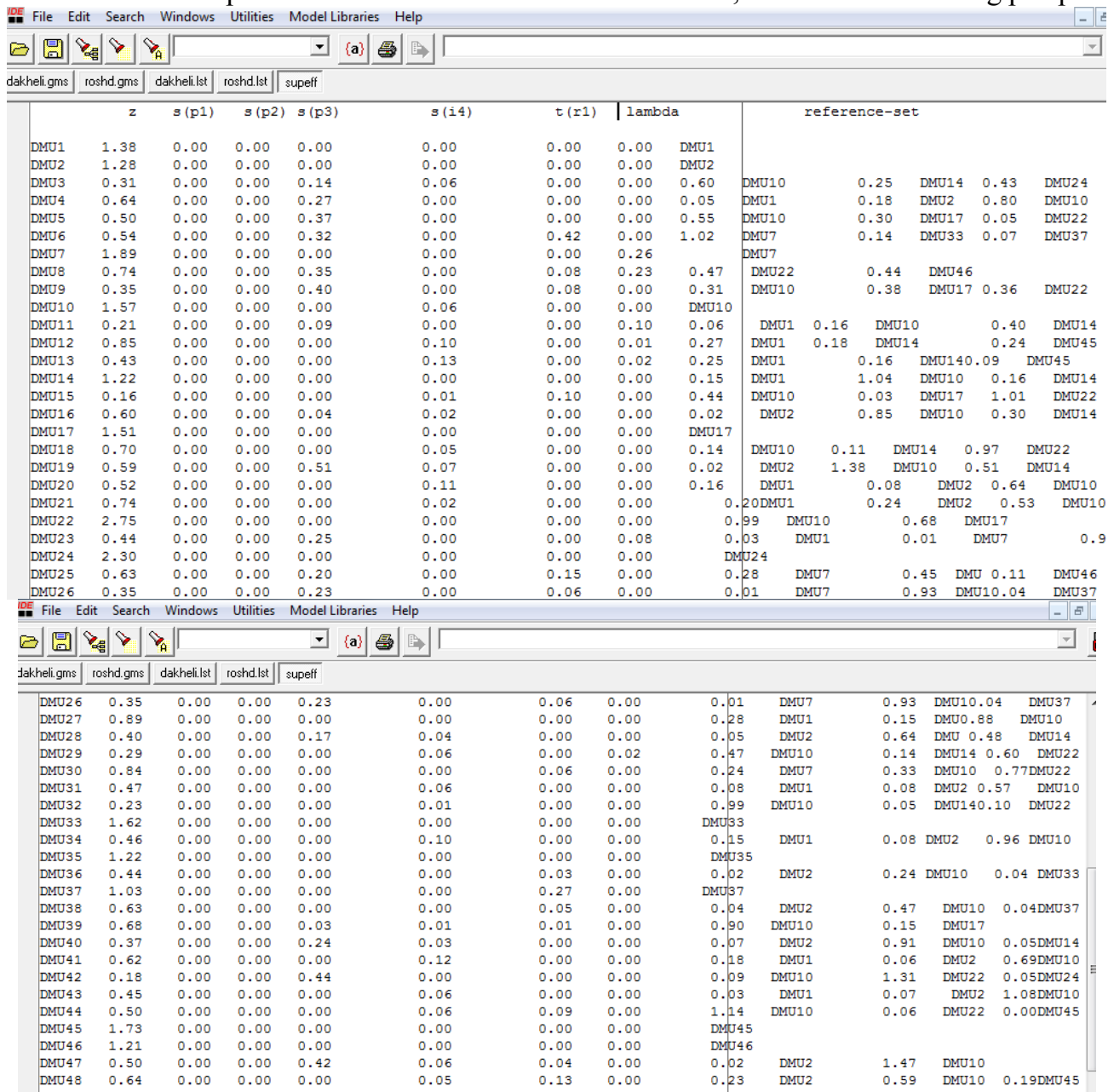

Based on the table, the technical efficiency score of the branch of "Khwaja Abdullah Ansari" in learning and growth perspective is 0.29 . In fact, the activity of the branch in the field of training and attracting innovation to 
create more value for customers and continuously improving the operational efficiency has been inefficient toward other branches.

The amounts of shortage in output to the amount 0.06 in the employees' training courses and 0.02 in the number of notes receivable toward the potential of the branch is the reason of inefficiency in mentioned branch. In fact, with the same amount of investment in the sources it can have more output and output. As described, DEA models allow the model units to be determined. For example, reference units of Pasdaran, Soheil, Mother square have been introduced as a model unit for the branch of Khwaja Abdullah Ansari. The weight of reference branch $\lambda$ is the coefficient which is given in table and indicates the participation rate of the reference branches in the assessment of inefficient branches. Finally, with the composition of mentioned reference units, a virtual unit will be achieved as follows:

$$
0.47\left[\begin{array}{l}
0.1 \\
0.021
\end{array}\right]+0.14\left[\begin{array}{l}
0.1 \\
0.1
\end{array}\right]+0.6\left[\begin{array}{l}
0.11 \\
0.01
\end{array}\right]=\left[\begin{array}{l}
0.12 \\
0.02
\end{array}\right]
$$

As can be seen, the inputs of virtual unit is equal to $\left[\begin{array}{l}0.12 \\ 0.02\end{array}\right]$, while the real input of the branch of Khwaja Abdullah Ansari is $\left[\begin{array}{l}0.43 \\ 0.1\end{array}\right]$. According to the results, Table 2.4.1.1 shows the surplus amounts of use in resources related to the model of enveloping input-oriented super-efficient. The ranking of efficiency units for learning and growth perspective is as follows:

Table 5: The ranking of efficiency units for learning and growth perspective

\begin{tabular}{|c|c|c|}
\hline Efficiency Score & Branch Name & Unit \\
\hline 2.75 & Mother Square & 22 \\
\hline 2.30 & Valiasr Abshar & 24 \\
\hline 1.89 & Velenjak & 7 \\
\hline 1.73 & Park St. & 45 \\
\hline 1.57 & Pasdaran & 10 \\
\hline 1.51 & Seyyed Jamal Al-din Asad Abadi St. & 17 \\
\hline 1.38 & Anahita & 1 \\
\hline 1.22 & Soheil & 14 \\
\hline 1.21 & Sheikh Bahaei St. & 46 \\
\hline 1.03 & Moghaddas Ardebili St. & 37 \\
\hline
\end{tabular}

\section{Conclusion}

The main problem of present research is to select the appropriate indicators for DEA technique and measure the efficiency of banks, not only from financial aspects, but also from other perspectives as well. That the model BSC was used to moderate this challenge in order to measure the technical efficiency of banks. On the other, traditional models of DEA technique are not capable to announce the score of efficient units more than one. Super efficient models of DEA technique were used to mitigate this challenge which they are capable to announce the efficiency score and rank the efficient units simultaneously. So, we measured the technical efficiency of 48 top and grade-one Melli bank branches in northern Tehran by the model of return in constant scale of enveloping input-oriented super-sufficient in four perspective of DEA model. The results showed that average efficiency rate from four perspectives: financial, customer, internal process and learning and growth of BSC model is $0.68,0.63,0.44,0.65$, respectively, and in total, the average efficiency of branches is 0.6 in this year and it indicates that the most major alignment with macro- strategies of branches is in the financial perspective. Also, Anahita branch was introduced as the most efficient unit from each four perspectives of the BSC model in compared to the other branches. After determining the efficient units from every 4 aspects of balanced scored card, model units were introduced. Given the research aims at analyzing, the results of Zafar St. branch showed that based on the results of technical efficiency score the financial is 1.21 , customer 0.61 , internal process 0.36 , and growing and learning 0.5 .These scores for this company indicate the local efficiency of the branch during the provision of service. Because this branch has taken steps in order to profitability and maintain shareholder value by adopting short-term strategies and due to the lack of attention to marketing issues to attract customers, use of advanced technologies in the internal process perspective, also due to the lack of adequate attention to the part of human resources to enhance the employees' skills, are factors that indicates the 
short-term profitability of the branch, that finally model units were also determined for each perspective. Finally, banking industry is considered as strategic industry, during the modeling according to calculations carried out for the final decision, the opinions of bank professionals and experts should be used for appropriate allocation of resources.

\section{Reference}

[1]. Avkiran, Necmi K, (2011), "Association of DEA super-efficiency estimates with financial ratios: Investigating the case for Chinese banks" Omega 39, PP. 323-334

[2]. Chen,Tser-yieeh,andChen,Chin-Bein (2008), "Firm operation performance and analysis with data envelopment analysis and balanced score card" International Jornal of production performance management,vol,57,no7,pp.523-539

[3]. Grigoroudis, E., Orfanoudaki, E., \&Zopounidis, C. (2012). Strategic performance measurement in ahealthcare organization: A multiple criteria approach based on balanced score. Omega, 40, 104-119.

[4]. Joo, S. J. and Nixon, d. and Stoeberl, P. A., (2011)“Benchmarking with data envelopment analysis: a return on asset perspective", Benchmarking: An International Journal, Vol. 18 No. 4, PP. 529-542

[5]. Khakia, Amir Reza and Najafib, SeyedEsmaeel and Rashidia, Sadra (2012)“Improving efficiency of decision making units through BSC-DEA technique” Management Science Letters 2 (2012) ,PP.245-252

[6]. .Koo Hannah ,Ka-Yin Chau,Koo Leung-Chi ,Liu SongbaiShu-ChuenTsui(2011)"A structured SWOT approach to develop strategies for the government of Macau, SAR"Journal of Strategy and Management Vol. 4 No. 1, pp. 62-81

[7]. Lai, Mei-Chi and Huang ,Hao-Chen and Wang, Wei-Kang, (2011) "Designing a knowledge-based system for benchmarking: A DEA approach" Contents lists available at Science Direct, PP 662-671.

[8]. Min, Hokey and Joo ,Seong Jong and Kim, Joungman (2008) "Evaluating the financial performances of Korean luxury hotels using data envelopment analysis" International Journal of quality \& reliability management, vol 25,no4,pp349-365

[9]. Prrigot . R\&Cliquet. G \&Lepetit.I (2009). "Plural from chain and efficiency: Insight from the chains and the DEA methodology" Europian Management Journal,27,pp268-280 